\section{OIL POLLUTION}

\section{Prospect of Indemnity}

WHat seems to be a legal innovation of unexpected force for dealing with oil pollution is in prospect as part of a compromise between the Publio Works Committee of the House of Representatives and Senator Edmund Muskie's subcommittee on air and water pollution. After several months of consideration of alternative ways of making oil and shipping companies responsible for the damage done by marine pollution, it seems probable that the two committees will recommend legislation making those responsible for oil leakages absolutely responsible, whether they have been negligent or not. A year ago, the House of Representatives passed a bill making shipowners or operators responsible for the cost of cleaning up after oil discharges within United States waters if they "wilfully or negligently" caused this pollution. The Senate subcommittee has consistently taken the line that this is not sufficiently fierce, especially because it would turn out in practice that the onus of proving negligence would rest with the United States government. This is why the Senate in October took the view that absolute liability is the only defence against oil pollution. Apparently it has nevertheless been accepted that shipowners would not automatically be liable for the cost of cleaning up pollution if an oil spill were caused either by some natural disaster such as a hurricane or by the faulty marking of a navigation channel.

The extent to which shipowners will be able to insure against their liabilities under this new provision will only be apparent when the financial basis for compensation has been settled. One arrangement that has been talked of is that there should be a limit of $\$ 100$ per gross ton or a lump sum of $\$ 14$ million. The figure of $\$ 100$ a ton is apparently that which the insurance companies consider reasonable. By this test, most tankers would be required to insure themselves to the tune of $\$ 100$ a ton. Another innovation is that companies drilling for oil in territorial waters should also be liable for the cost of cleaning up aftcr an accidental release of oil. There is some danger that the toughness of these proposals may eventually stick in the throat of the House of Representatives when the compromise bill comes to be discussed.

\section{SPACE}

\section{Apollo 13 seeks Age of the Moon}

Wттн two geological traverses planned in detail for the Apollo 13 astronauts James Lovell and Fred Haise, the mission that begins next weekend is more strongly oriented towards scientific research than was either of its predecessors. But the success of the carefully thought out programme depends on setting down the lunar module at precisely the right spot. This was achieved by Charles Conrad and Alan Bean in Apollo 12 with unexpected ease in the smooth plains of Oceanus
Procellarum, but will be harder in the rough hills of the Fra Mauro formation. This is the area towards which Lovell and Haise, together with command module pilot Thomas Mattingley, will be heading when they set out from the Kennedy Space Center on April 11 (20.13 B.S.T.).

Believed to be composed of ejecta from Mare Imbrium to the north, the Fra Mauro hills are roughly midway between the Apollo 12 site and the centre of the visible face of the Moon. The planned landing site for Apollo 13 is about 110 miles from the Apollo 12 site and about 200 metres higher.

Two periods of activity outside the lunar module are planned for the interval between touchdown on the surface at 03.55 B.s.T. on April 16 and lift-off at 13.22 B.S.T. on the following day. During the second traverse the astronauts intend to recover some of the Fra Mauro bedrock, either by drilling or from the rim of a feature called Cone Crater excavated 300 feet into the Fra Mauro material. The hope is that this bedrock is ejecta from as deep as $100 \mathrm{~km}$ below Mare Imbrium, itself one of the oldest features of the Moon. With an age of 4,500 million years already recorded from the Apollo 11 samples, the Fra Mauro bedrock could well be 500 million years older, and there is speculation that the samples may force a revision of estimates of the age of the solar system.

Like the rest of the Moon, the Fra Mauro bedrock is blanketed by a layer of material from more recent processes such as the impact of meteorites. To penetrate this layer the Apollo 13 astronauts will be equipped to extract cores from a depth of about 10 feet, compared with cores of about thirty inches obtained by the Apollo 12 team. With luck the astronauts should also be able to pick up rocks excavated from the nearby craters Eratosthenes and Copernicus, and these will give more clues to the interior of the Moon.

The success of the two traverses which have been mapped out-the first of up to 5,000 feet and the second of about 8,700 feet-depends critically on the accuracy of touchdown. It is reasonable to expect that the precautions which were taken with Apollo 12 to ensure that the descent to the lunar surface bogan at the right place will be equally successful, and on this occasion the astronauts will have an extra fifteen seconds of hover time. To achieve the necessary reserve in the fucl tanks of the lunar module, the engine in the service module will be used to propel the command module with the lunar module still attached into an orbit of $7 \times 57$ nautical miles. The lunar module then begins its descent from the low point of the orbit, and one of the by-products of the manoeuvre will be close-up photographs from the command module as it passes over the crater Censorinus.

Two seismographs will be installod on the Moon to record the impact of the Apollo 13 ascent stage, expected to be about 42 miles to the west of the Fra Mauro site and 69 miles to the east of Apollo 12. A bonus for the seismologists will be the impact of the third stage of the Saturn V launcher, scheduled to occur on the front face of the Moon while Apollo 13 is being injected into lunar orbit behind the Moon. The third stage will follow the path of Apollo 13 from the Earth, and impact is plannod to bo about 124 miles west of the Apollo 12 seismograph. An impact at this distance from the seismograph should give more information about deeper layers of the Moon. 